УДК 69.003

\title{
СОКРАЩЕНИЕ ТРУДОЗАТРАТ И МАТЕРИАЛЬНЫХ РЕСУРСОВ ПРИ ПРИМЕНЕНИИ НОВЫХ ТЕХНОЛОГИЙ
}

\author{
Якубов Шамиль Гамдулахович \\ студент \\ Научный руководитель: Дикарева Варвара Андреевна \\ д.э.н., профессор \\ ФГБОУ ВО «Национальный исследовательский \\ Московский государственный строительный университет»
}

\begin{abstract}
Аннотация: На производственных предприятиях непрерывно используются различные виды материальных ресурсов. Совокупность затрат при приобретение новых технологий называется материальными затратами, являющимися одним из экономических элементов стоимости готовой продукции. Одной из задач субъекта хозяйствования производственной сферы выступает сокращение материальных ресурсов и трудозатрат на производство и реализацию продукции.
\end{abstract}

Ключевые слова: Производительность труда, нормирование труда, эффективность работы, расходование ресурсов материальные ресурсы.

\section{Yakubov Shamil Gamdullakhovich Dikareva Varvara Andreevna}

\footnotetext{
Abstract: Various types of material resources are continuously used in production enterprises. The total cost of acquiring new technologies is called material costs, which are one of the economic elements of the cost of finished products. Consequently, the lower the material costs, the lower the cost, which allows the company to increase the profit from the sale of products. One of the tasks of the business entity of the production sector is to reduce material resources for the production and sale of products.

Key words: Labor productivity, labor rationing, work efficiency, resource expenditure material resources.
} 


\section{СОВРЕМЕННЫЕ ТЕХНОЛОГИИ: ПРОБЛЕМЫ ИННОВАЦИОННОГО РАЗВИТИЯ И ВНЕДРЕНИЯ РЕЗУЛЬТАТОВ}

С течением времени тенденции, намечающиеся в развитии инновационных технологий, значительно меняются. Появляются новые перспективные разработки, проходят апробацию ранее выдвинутые идеи, делаются новые открытия, происходит диффузия нововведений. В результате ранее составленные промышленными предприятиями планы и стратегии подлежат корректировке, a ранее принятые управленческие решения относительно направления инновационного развития предприятия требуют пересмотра.

Для сохранения устойчивого положения промышленного предприятия на быстро меняющемся рынке анализ внешних условий должен носить не только ситуативный, но и системный, периодический характер.

Изменения, происходящие в мировой экономике, оказывают непосредственное влияние не только на экономическую и политическую ситуации, но и на науку и инновационную деятельность. Развитие технологий приводит не только к совершенствованию производственных процессов, оно провоцирует также необходимость пересмотра подходов к управлению промышленным предприятием в целом.

Научно-технический прогресс провоцирует и более масштабные изменения. Новые технологические решения проявляются не только в деятельности отдельных предприятий, в которых они возникают, но оказывают влияние на целые промышленные комплексы. Следствием этого становится изменение ситуации в регионе, оно может быть позитивным, но может приводить и к негативным последствиям. В связи с этим цель деятельности органов управления регионами состоит в обеспечении социально-экономического развития [2].

Создание условий для такого развития является комплексной деятельностью, направленной на разностороннюю поддержку экономических субъектов.

Производительность труда простыми словами - это показатель в экономике, позволяющий оценивать эффективность работы персонала. Когда производительность труда на предприятии высокая, уменьшаются затраты на выпуск продукции. Если в компании все именно так, можно говорить о высокой рентабельности производства.

Эффективностью труда называют достижение персоналом фирмы хороших показателей в работе при небольших затратах. Производительность 


\section{СОВРЕМЕННЫЕ ТЕХНОЛОГИИ: ПРОБЛЕМЫ ИННОВАЦИОННОГО РАЗВИТИЯ И ВНЕДРЕНИЯ РЕЗУЛЬТАТОВ}

труда на предприятии характеризуется эффективностью труда в материальном производстве, объемом выпускаемых товаров за определенный промежуток времени и затратами труда, которые необходимы для производства единицы продукции.

В чем же заключается эффективность использования оборотных средств? Принцип рационализации использования оборотных средств экономия материальных ресурсов. .Материальные ресурсы должны составлять большую часть системы оборотных средств, соответственно их эффективное использование позволяет предприятию получать существенную выгоду. Например, снижение использования таких ресурсов на единицу продукции приведет к большему количеству реализуемых товаров. Очевидно, такое снижение должно быть соразмерным - с учетом сохранения качества продукции, его функциональных характеристик. Экономия материальных ресурсов побуждает предприятие рационализировать производственный процесс, что будет заключаться во внедрении новых технологий, автоматизации производства, увеличении производственных мощностей, тем самым увеличивая объем производственного цикла. Все перечисленное положительно влияет на финансовую отдачу на этапе реализации, что непременно ведет к экономическому росту предприятия. Можно сделать вывод, что оптимизация расхода материальных ресурсов является важнейшей задачей управления оборотными средствами, т.к. это напрямую влияет на финансовое состояние предприятия.

Эффективность использования оборотных средств также важна на стадии реализации. На этой стадии завершается экономический цикл предприятия, и ранее авансированные денежные средства должны быть компенсированы для начала нового. Здесь наиболее ярко можно рассмотреть необходимость управления фондами обращения, которые и обслуживают процесс реализации. Задачей управления оборотными средствами, будет являться эффективное использование денежных потоков, нереализованной продукции, и контроль дебиторской задолженности, которые должны компенсировать их отток в начало нового производственного цикла (оплата подрядчиков, поставщиков, переход в основной капитал). Грамотное использование денежных потоков напрямую связано с технологическим предпринимательством. 


\section{СОВРЕМЕННЫЕ ТЕХНОЛОГИИ: ПРОБЛЕМЫ

Технологическое предпринимательство - это инвестирование финансовых, интеллектуальных и человеческих ресурсов в специфические активы (новые физические или программные продукты), основанные на актуальных достижениях и знаниях в областях науки и техники (knowledgeintensive идеях). Эти активы создаются с целью повышения максимальной стоимости и эффективности работы компании или предприятия.

Деятельность, связанная с технологическим предпринимательством, имеет свою специфику:

- знания и технологии задействуются для оформления новых knowledge-intensive идей или для их приспособления к практическому применению;

- работа в отраслях стартапов предусматривает объединение технологий и ресурсов и проведение совместных экспериментов и исследований, производство новых продуктов, связанных с научнотехническими достижениями и созданием интеллектуальных активов;

- направленность на выявление актуальных нерешенных проблем, задач и способов применения той или иной технологии.

Одним из направлений этой деятельности являются технологические стартапы, связанные не только с разработкой принципиально новых продуктов и использующие knowledge-intensive, но и занятые усовершенствованием или комбинацией уже существующих разработок. В России технологические стартапы в основном развиваются в сферах IT, еcommerce и финтеха.

Процесс создания технологического стартапа включает следующие этапы:

этап идеи - формирование инженерной и коммерческой гипотез о том, какой категорией покупателей будет востребован будущий продукт и какие технические решения могут понадобиться для его изготовления;

этап прототипа - «материализация» идеи в рабочем функционале;

этап продукта - окончательная отладка программных или инженерных решений, приобретение материальных ресурсов (при необходимости).

С коммерческой точки зрения этап продукта предполагает его встраивание в деятельность будущих потребителей через процесс легализации (сертификации), как полностью подготовленного к безопасной эксплуатации и 


\section{СОВРЕМЕННЫЕ ТЕХНОЛОГИИ: ПРОБЛЕМЫ ИННОВАЦИОННОГО РАЗВИТИЯ И ВНЕДРЕНИЯ РЕЗУЛЬТАТОВ}

запуск предпродаж и реального сбыта с возможностью получения предоплаты.

Далее рассмотрим аспекты сокращения трудозатрат.

Инновационный элемент в структуре нормирования труда достигается путем применения:

- современных методов анализа процесса производства;

- нестандартных подходов к проектированию технологий трудовых процессов.

Большую роль играет учет автоматизации и усовершенствования технологий процесса труда. Таким образом, необходимо отметить, что процесс нормирования труда не является стационарным явлением, он должен быть связан с внедряемыми изменениями и строится с их учетом.

Сферы применения нормирования труда на современном этапе:

- трудоемкие процессы - разработка норм трудоемкости производственного процесса;

- планирование численности персонала - определение потребностей в определенных категориях персонала, рабочих определенных профессий и квалификации;

- разработка и совершенствование системы оплаты труда - оценка эффективности труда, определение трудового вклада работников, увязка оплаты труда со сложностью, трудоемкостью и прочими характеристиками выполняемых операций;

- анализе эффективности внедрения новой техники и технологий;

- разработке технологий повышения производительности труда;

- планировании закупок нового оборудования;

- оценке условий труда и рабочих мест.

Таким образом, нормирование труда затрагивает все сферы организации труда на предприятии. Именно при помощи методов нормирования можно рассчитать экономическую обоснованность тех или иных нововведений. Основным методом, который применяется при нормировании труда выступает аналитический метод.

В сложных экономических условиях, когда падает уровень производства, снижается финансовый результат важно построить систему мотивации и стимулирования так, чтобы найти компромисс между 


\section{СОВРЕМЕННЫЕ ТЕХНОЛОГИИ: ПРОБЛЕМЫ ИННОВАЦИОННОГО РАЗВИТИЯ И ВНЕДРЕНИЯ РЕЗУЛЬТАТОВ}

интересами предприятия и сотрудников. Все чаще при разработке положений об оплате труда осуществляется привязка конечных результатов деятельности к объемам стимулирующих выплат. [1]

Для повышения эффективности работы в компании необходимо снизить трудозатраты на производство единицы продукции. Достичь этого можно различными способами. Основное условие - сокращение трудовых издержек. Нужно, чтобы работа фирмы была организована бесперебойно, без простоев. Такие пути повышения производительности труда на предприятии приведут к улучшению эффективности работы.

Еще один вариант - сократить время оборота продукции. Это довольно сложно, но реально. При этом внедряются не только новые линии и станки (благодаря которым производственный процесс становится автоматизированным, а значит более быстрым), но и уменьшается дебиторская задолженность, а продукцию удается продать скорее.

Нередко пользуются и такими методами, как:

1. Автоматизация труда. Направлена на повышение производительности труда работников предприятия и общей продуктивности, а также на снижение издержек.

2. Использование механизма управления и накопления знаний, чтобы инженеры, менеджеры и мастера работали более эффективно.

3. Уменьшение различных непроизводственных затрат. Требуется проведение аудита существующих расходов и выделение пунктов, отказ от которых возможен.

4. Точное понимание коллективом своих задач и должностных обязанностей, а также их оптимизация.

5. Улучшение условий труда, создание рабочим комфортных условий и стабильности. Когда на работе царит дружеская атмосфера, мастера будут работать даже за меньший оклад по сравнению с тем, что предлагают конкуренты.

6. Мотивация. Без мотивации повышения производительности труда работников предприятия не будет.

7. Повышение лояльности сотрудников. Для руководства очень важно наладить общение с сотрудниками, показать готовность прийти на помощь и решить возникшие проблемы. 8.Контроль. Требуется проработка системы 


\section{СОВРЕМЕННЫЕ ТЕХНОЛОГИИ: ПРОБЛЕМЫ ИННОВАЦИОННОГО РАЗВИТИЯ И ВНЕДРЕНИЯ РЕЗУЛЬТАТОВ}

контроля за итоговым результатом. Именно на нее следует опираться, оценивая производительность труда на предприятии.[4]

Подводя итог, можно сказать, что хозяйственное значение экономии материальных ресурсов (снижения удельных норм расхода сырья, материалов, топлива, энергии и т. д.) велико и многообразно.

Во-первых, экономия расходования средств производства хотя бы на одном участке производственной подсистемы логистики обязательно влечет за собой повышение общественной производительности труда. В самом деле, если на каком-либо этапе обработки продукта уменьшаются материальные затраты, то общие суммарные затраты живого и овеществленного труда, затрачиваемые на изготовление единицы продукта, уменьшатся.

Во-вторых, экономия сырья, материалов, топлива и энергии, выражающаяся в уменьшении расхода материалов на единицу продукции (или на единицу работы), позволяет при неизменном количестве средств производства выпустить большое количество конечного продукта, т. е. увеличить объем выпуска. Это обстоятельство становится особенно существенным, если речь идет о дорогостоящем сырье или материалах.

В-третьих, экономное расходование материальных ресурсов и уменьшение удельных норм расхода сырья и материалов на единицу выпускаемой продукции очень важный фактор при осуществлении мероприятий по снижению себестоимости производства и повышению рентабельности.

В качестве основных направлений экономии материальных ресурсов промышленного предприятия целесообразно определить:

- повышение уровня технологии;

- повышение требований к парку основного оборудования;

- повышение квалификации персонала;

- совершенствование организации;

- развитие систем анализа, планирования;

- совершенствование нормативной базы и т.д. [3]

\section{Список литературы}

1. Кравченко О.В. Применение современных методов организации, нормирования и оплаты труда на предприятии // Современные научные 
исследования и инновации. 2019. № 11 [Электронный ресурс]. - URL: https://web.snauka.ru/issues/2019/11/90458 (дата обращения: 08.06.2021). (дата обращения 8.06.2021)

2. Никонорова А. В. Тенденции в развитии технологий и их влияние на управление промышленными предприятиями Текст научной статьи по специальности «Экономика и бизнес» Никонорова А. В. - URL: https:// cyberleninka.ru/article/n/tendentsii-v-razvitii-tehnologiy-i-ih-vliyanie-naupravlenie-promyshlennymi-predpriyatiyami (дата обращения 8.06.2021)

3. Основные направления экономики материальных ресурсов - URL: https://shveyndvrk.ru/technology/osnovnye-napravleniya-ekonomiki-materialnyhresursov-napravleniya-ekonomii/ (дата обращения 8.06.2021)

4. Факторы, влияющие на уровень производительности труда URL: https:// www.gd.ru/articles/3575-proizvoditelnost-truda(дата обращения 8.06. 2021)

5. Юфкина Ю. Е. Оборотные средства предприятия и эффективность их использования- URL: https://sci-article.ru/stat.php?i=1621253142 (дата обращения 8.06.2021). 